\title{
Early intervention for Conversion Disorder: neurologists and psychiatrists working together.
}

Selma Aybek ${ }^{1}$

Monica Hubschmid ${ }^{2}$

Corinna Mossinger ${ }^{1}$

Alexandre Berney²

François Vingerhoets ${ }^{1}$

${ }^{1}$ Neurology Service, Clinical Neuroscience Department, CHUV, Lausanne, Switzerland

2 Liaison Psychiatry Service, Psychiatry Department, CHUV, Lausanne, Switzerland

Corresponding author:

Selma Aybek

Service de Neurologie, BH13

Bugnon 44

1011 Lausanne

Tel: +417955678716

selma.aybek@chuv.ch

This article has been accepted for publication and undergone full peer review but has not been through the copyediting, typesetting, pagination and proofreading process which may lead to differences between this version and the Version of Record. Please cite this article as an 'Accepted Article', doi: 10.1111/j.1601-5215.2012.00668.x 


\section{ABSTRACT}

Objective: To evaluate the efficacy of an early multidisciplinary (neurology and psychiatry) intervention for Conversion Disorder (CD).

Methods: Consecutive patients newly diagnosed with CD from 2005 to 2007 were compared to a control group of newly diagnosed CD patients receiving usual care. At 3 years, a questionnaire evaluated self-rated subjective outcome, symptom severity, SF-36 scores, employment status and medical care use.

Results: Data from 12 cases (mean age 25.5ะ8.2; 9 females) and 11 controls (mean age $34.7 \pm 13.5$; 10 females) showed that $83 \%$ of cases had a good subjective outcome (symptom improved or cured) when only $36 \%$ of controls had a good outcome $(\mathrm{p}<0.05)$. Cases significantly improved their SF-36 scores on subscales involving physical complaints compared to controls. A minority (20\%) of cases reduced or ceased professional activity when $70 \%$ of controls did $(\mathrm{p}<0.001)$. Only $16 \%$ of cases sought further medical advice for the initial symptom when $73 \%$ of controls did. Both groups accepted psychiatric referrals (83\% of cases and $73 \%$ of controls) and found it beneficial.

Conclusions: Early intervention involving both neurologists and psychiatrists is effective for CD in alleviating physical complaints, reducing sick leave and health care use.

Keywords: conversion disorder, functional neurological symptoms, treatment, outcome

\section{Significant outcomes:}

- A high proportion (73-83\%) of Conversion Disorder patients accept psychiatric referral.

- Only patients who had a structured multidisciplinary joint program (psychiatric and neurological follow-ups) had a long-term (3years) good outcome. 
- Unstructured psychiatric treatment alone is not sufficient for Conversion Disorder, that seem to benefit from an early support involving both psychiatric and neurological interventions.

\section{Limitations}

- The results of this study are highly significant but rely on a small sample of patients and might not be generalised to other Conversion Disorder population.

- The two groups were not randomised and a selection bias could have happened towards better cases allocated to the treatment group.

- The outcome measures rely on patient's report and are prone to subjective evaluation. 


\section{INTRODUCTION}

Functional neurological symptoms are frequently encountered in neurology [1] and represent an enormous challenge in terms of treatment, as they bear a poor prognosis[2] and are costly in terms of health care system[3] and employment[4]. Despite spectacular advances in neuroscience, no definite biological etiologic model has emerged[5] and functional neurological symptoms are understood as "psychogenic" [6] or thought to be part of psychiatric illnesses, as reflected by both DSM-IV Conversion disorders (CD) or CIM-10 Dissociative disorders definitions. Neurologists often refer patients with functional symptoms to psychiatrists[7] and both specialists admit they find those patients difficult to handle[8]. Several psychosocial therapeutic approaches have been tried such as hypnosis[9], paradoxical injunction therapy[10], individually tailored psychotherapy[11] and cognitive behavioural therapy[12], but no definite treatment plan can be recommended[13]. One of the major difficulties in those approaches lies in the fact that patients do not see themselves as psychiatric patients[14], as they suffer from a physical symptom. When a psychiatric referral is offered, they feel rejected by their neurologists and tend to seek further medical advice[15]. A multimodal approach- combining physical revalidation and psychological intervention has shown some benefit in $\mathrm{CD}[16]$. In this context and in order to avoid the above mentioned issues, a joint consultation, including a neurologist and a psychiatrist, was implemented in our tertiary centre in 2005 (University Hospital, Lausanne), dedicated to the management of patients diagnosed with CD.

The aim of this study was to evaluate the impact of this treatment plan on the long-term outcome of patients. 


\section{METHODS}

\section{Subjects selection: “Joint consultation group”}

All consecutive patients followed at the joint consultation from 01.01.2005 to 30.09.2007 were included. They were all newly diagnosed with CD (DSM-IV criteria) after thorough neurological and psychiatric assessments. The treatment plan consisted of a neurological follow-up assessment, followed by a psychiatric interview and at the end a common discussion with the patient, the neurologist and the psychiatrist was held. No predefined number of consultations was set but the treatment plan was tailored to the patient needs. The aim of the joint consultation was to explain the functional nature of the symptoms, offer coping strategies and address the potential role of psychological factors.

\section{Controls selection: "Standard care control group"}

Patients with new onset CD who were not followed up at the joint consultation during the same period were identified through retrospective chart review of all in- and

outpatients. Electronic patients database was reviewed with the search terms "psychogenic", "functional", "dissociative", "somatoform" and "conversion". Once a diagnosis was established, patients were discharged with a summary to their general practitioner, stating the diagnosis and suggesting psychiatric referral.

\section{Intervention}

A postal questionnaire was sent in December 2009 to all subjects, and phone calls were made to those who did not respond to either confirm their refusal or propose them to fill in the questionnaire by phone. The questionnaire included the SF-36, employment status, medical care use and self-ratings of symptoms severity. Subjects were asked to rate on a $0-10$ Likert scale how severe their symptoms were at first presentation and how severe they were at the time of questionnaire. 


\section{Analysis}

Across group analysis were done by comparing the mean or median scores with MannWhitney U-tests. Between group analysis of score changes over time were done with paired Wilcoxon test.

\section{RESULTS}

From 01.01.2005 to $30.09 .2007,17$ patients were enrolled in the joint consultation program. Two patients were lost to follow-up, 3 refused and 12 responded.

During the same period, 28 charts were identified with the above mentioned search terms but only 17 fulfilled the DSM-IV criteria for CD. In the other cases, search terms were present because CD was raised in the differential diagnosis. Two subjects were lost to follow-up, 4 refused to take part and 11 responded.

Demographic data did not differ between groups, which had similar female/male ratio and symptom types (Table 1). The joint consultation group tended to be younger but

the mean age was not significantly different between groups $(25.5 \pm 8.2 ; 34.7 \pm 13.5$; $\mathrm{p}=0.07$ for joint consultation and standard care groups respectively). The median time from first symptom to diagnosis was similar in both groups (11days; 14 days; $\mathrm{p}=0.81$ ), as well as the time elapsed from diagnosis to follow-up questionnaire (3.6years; 3.1years; $\mathrm{p}=0.09$ ). The joint consultation group had a mean number of follow-up consultations of 2.8 .

The majority of patients from the joint consultation group reported a good long-term outcome $(83 \%)$ when only $36 \%$ of the standard care group did $(p=0.005)$. Both groups rated their initial symptoms as equally severe ( 9 versus $8, p=0.64$ ) but only the joint consultation group reported a significant change in symptoms severity (from 9 to 1; $\mathrm{p}<0.01$ versus from 8 to $7, \mathrm{p}=0.34$ ). Only $20 \%$ of patients from the joint consultation 
group reduced or ceased professional activity because of initial symptoms when $70 \%$ of the patients from the standard care group did $(\mathrm{p}<0.05)$.

Patients from the joint consultation group had better SF-36 scores on physical functioning, social functioning, general health and less limitation of their activities due to physical symptoms. No differences were found in terms of mental health or limitation of activities due to emotional symptoms, nor in energy level or pain. In order to compare the SF-36 scores to what can be expected in the general population, the normal range in the local population(17] are presented in Table 1 but no statistical analysis was carried out. It appears that patients from the joint consultation group reach a normal level for physical functioning, even though they still have lower scores for general health, compared to the healthy local population.

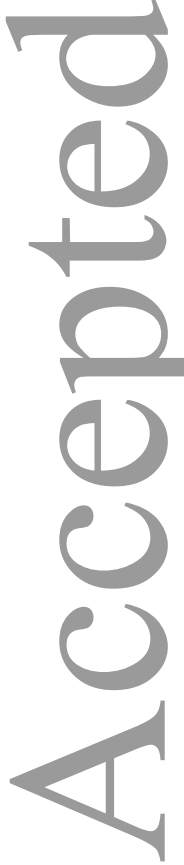

In terms of understanding the disease, both groups considered their initial diagnosis as rather unclear or completely unclear $(50 \%$ and $82 \%$ respectively for the joint consultation and control group, $\mathrm{p}=0.12$ ) but a significant smaller proportion of patients from the joint consultation group sought further medical advice (16\% versus $73 \%$, $\mathrm{p}<0.01$ ) (details in Table 1). A majority of patients in both groups agreed to a psychiatric referral (83\% versus $73 \%, \mathrm{p}=0.55)$ and considered this psychiatric intervention beneficial ( $90 \%$ versus $100 \%, \mathrm{p}=0.78$ ). Patients from the joint consultation group had a mean number of additional (after the joint consultation program was over) psychiatric interviews of 41 , when patients from the standard care group had a mean of 44 interviews $(p=0.9)$. A majority of patients followed-up in the joint consultation judged the intervention to be beneficial (75\%).

\section{DISCUSSION}


This controlled, questionnaire-based, follow-up study showed that at 3 years the group of $\mathrm{CD}$ patients enrolled in a standardized program involving joint consultations (neurologist and psychiatrist) had a better subjective outcome with a decrease of selfrated symptom severity, compared to standard care patients. This improvement of physical symptoms was also reflected in the results of the SF-36 questionnaire, showing a significant difference between groups in the subscales involving physical complaints. Objective measures, such as employment status and medical care use also showed a benefit of this program, as a greater proportion of treated patients returned to work and reduced their medical care use.

Our data show that overall, patients with CD had a high acceptance rate for further psychiatric referral, as both groups agreed to psychiatric evaluation with similar numbers of follow-up consultations and even judged it to be beneficial. However, patients who had psychiatric treatment outside the joint consultation program did not improve their physical symptom. This suggests that unspecific psychiatric intervention is not sufficient for CD patients and that the benefit we observe in our study might be due to the targeted goals defined- coping strategies and identification of psychological triggering factors. This is in line with previous work[11] showing that tailored psychotherapy, focussing on unresolved issues from the past and coping styles might be efficient in functional neurological symptoms. The second significant finding of our study is that patients from the joint program reduced their health care use compare to controls. Our structured program offered early standardized psychiatric intervention in the first weeks after symptom onset, whereas we do not have data on the time elapsed from first symptoms to first psychiatric intervention in the controls group. One could hypothesize that controls had a delay in their psychiatric care that led them to seek further medical help in the meantime. However, as the third goal of the joint program 
was to provide reassurance that no other organic cause can be found through repeated medical examination and discussions with the neurologist, this effect could also suggest that the presence of a neurologist is crucial in providing this reassurance and that reduced health care use is a positive consequence of this reassurance. A better understanding of the disease - and attribution to psychological causes- is a recognized predictor of good outcome[18] and one could hypothesize that the positive effect we measure is due to an improvement of understanding of the disease in patients followed at the joint program. Both groups rated their initial diagnosis as being rather unclear and, unfortunately, our questionnaire did not include an evaluation of disease understanding after treatment but the reduction in health care use is an indirect measure of acceptance of the proposed diagnosis.

Our study has several limitations. As the control group was selected based on retrospective chart reviews rather than randomized prospective attribution, a bias could have happened towards cases with better prognosis allocated to the joint consultation group, like patients with isolated CD without comorbid somatization. However, no significant differences were observed between groups at baseline regarding the other major known prognostic factors[2, 19, 20]; time to diagnosis, type of symptoms or baseline symptom severity. As all cases were newly diagnosed, a proportion of cases might have had a spontaneous positive outcome independent from the intervention. However, as both groups had similar times from first symptom to diagnosis, one could expect this effect to be minimized. Another limitation is that our outcome measures are subjective, as they rely on patients' self-reports and could have been influenced by unrealistic recall of baseline symptoms severity. Finally, as the exact content of the psychiatric intervention in the standard care group is not available, the differences in outcome we measure might not be due only to the procedure (joint 
consultation) itself as described above but could also be partly explained by a different type of psychiatric treatment. To better refine the effect of the psychiatric approach, a prospective study is needed.

This study however, demonstrates that a joint consultation program is well accepted by the patients, is effective in alleviating the physical symptoms, allows a better social functioning and reduces unnecessary medical investigations. The proposed intervention has minimal requirement- a psychiatrist and a neurologist ready to work together- and in the era of sophisticated medicine, such simple non-invasive treatment strategies should be maintained and developed by clinicians, as they seem to be useful to patients and cost-effective.

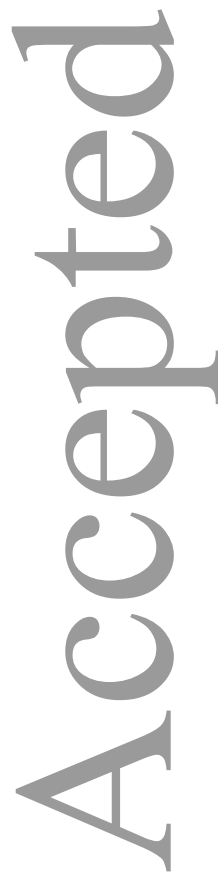


Table 1: Demographic and outcome data

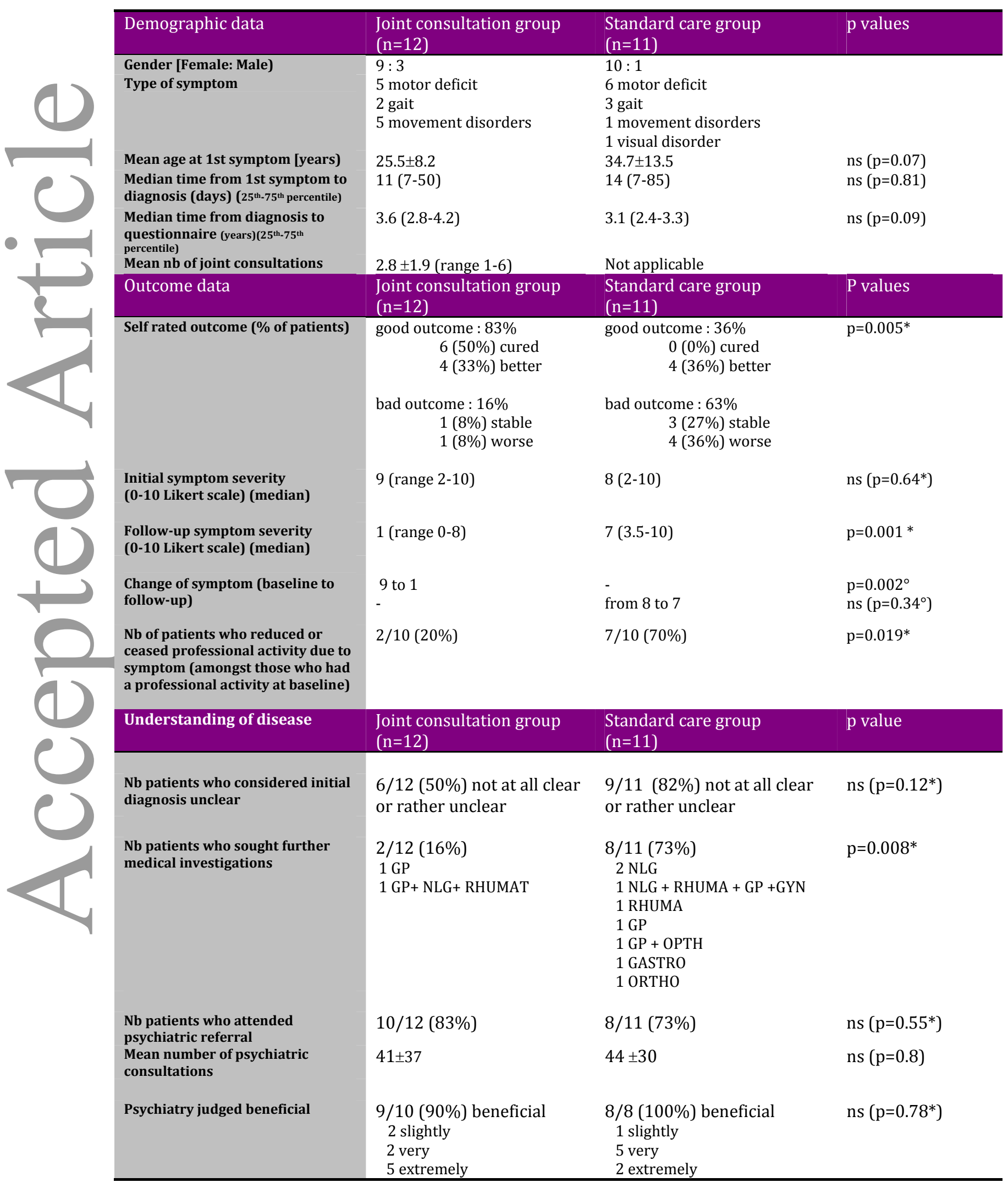




\begin{tabular}{|c|c|c|c|c|}
\hline & $\begin{array}{l}1 / 10(10 \%) \text { not at all } \\
\text { beneficial }\end{array}$ & \multicolumn{3}{|c|}{$\begin{array}{l}0 / 8(0 \%) \text { not at all } \\
\text { beneficial }\end{array}$} \\
\hline $\begin{array}{l}\text { Joint consultation judged } \\
\text { beneficial }\end{array}$ & $\begin{array}{l}9 / 12(75 \%) \text { beneficial } \\
6 \text { slightly } \\
1 \text { very } \\
2 \text { extremely }\end{array}$ & \multicolumn{3}{|c|}{ Not applicable } \\
\hline & \multicolumn{4}{|l|}{$\begin{array}{l}3 / 12(25 \%) \text { not at all } \\
\text { beneficial }\end{array}$} \\
\hline $\begin{array}{l}\text { SF-36 scores } \\
\text { Mean(SD) }\end{array}$ & $\begin{array}{l}\text { Joint consultation } \\
(\mathrm{n}=12)\end{array}$ & $\begin{array}{l}\text { Standard Care } \\
(\mathrm{n}=11)\end{array}$ & $\mathrm{p}$ value & $\begin{array}{l}\text { Normal populationa } \\
(\mathrm{n}=1250)\end{array}$ \\
\hline Physical functioning & $83(28)$ & $57(27)$ & $\mathrm{p}=0.021$ & $84(23)$ \\
\hline Role physical & 67 (39) & $28(26)$ & $\mathrm{p}=0.017$ & $75(36)$ \\
\hline Social functioning & $74(35)$ & $48(25)$ & $\mathrm{p}=0.033$ & $78(22)$ \\
\hline Bodily Pain & $72(37)$ & $47(36)$ & $\begin{array}{l}\text { ns } \\
(p=0.10)\end{array}$ & $72(24)$ \\
\hline Mental health & $59(23)$ & $44(13)$ & $\begin{array}{l}\text { ns } \\
(p=0.09)\end{array}$ & $68(19)$ \\
\hline Role emotional & $67(45)$ & $64(46)$ & ns $(p=0.9$ & $74(36)$ \\
\hline Energy /Vitality & $46(24)$ & $35(18)$ & $\begin{array}{l}\text { ns } \\
(p=0.26)\end{array}$ & 57 (18) \\
\hline General health & $56(27)$ & $25(16)$ & $p=0.006$ & $71(20)$ \\
\hline
\end{tabular}

ns= non significant

*Mann-Whitney U test

'Wilcoxon test

aSF-36 scores from the general local population (17)

$\mathrm{NLG}=$ neurologist

RHUMA= rheumatologist

$\mathrm{GP}=$ general practitioner

GYN=gynaecologist

OPTH= ophthalmologist

GASTRO = gastroenterologist

ORTHO $=$ orthopaedist 


\section{References}

1. Carson AJ, Ringbauer B, Stone J, McKenzie L, Warlow C, Sharpe M. Do medically unexplained symptoms matter? A prospective cohort study of 300 new referrals to neurology outpatient clinics. Journal of neurology, neurosurgery, and psychiatry. 2000;68(2):207-10.

2. Carson AJ, Best S, Postma K, Stone J, Warlow C, Sharpe M. The outcome of neurology outpatients with medically unexplained symptoms: a prospective cohort study. Journal of neurology, neurosurgery, and psychiatry. 2003;74(7):897-900.

3. Reid S, Wessely S, Crayford T, Hotopf M. Frequent attenders with medically unexplained symptoms: service use and costs in secondary care. The British journal of psychiatry : the journal of mental science. 2002;180:248-53.

4. Carson A, Stone J, Hibberd C, Murray G, Duncan R, Coleman R, et al. Disability, distress and unemployment in neurology outpatients with symptoms 'unexplained by organic disease'. Journal of neurology, neurosurgery, and psychiatry. 2011;82(7):810-3.

5. Nicholson TR, Stone J, Kanaan RA. Conversion disorder: a problematic diagnosis. Journal of neurology, neurosurgery, and psychiatry. 2010.

6. Hallett M. Psychogenic movement disorders: a crisis for neurology. Curr Neurol Neurosci Rep. 2006;6(4):269-71.

7. Espay AJ, Goldenhar LM, Voon V, Schrag A, Burton N, Lang AE. Opinions and clinical practices related to diagnosing and managing patients with psychogenic movement disorders: An international survey of movement disorder society members. Movement disorders : official journal of the Movement Disorder Society. 2009;24(9):1366-74. 
8. Carson AJ, Stone J, Warlow C, Sharpe M. Patients whom neurologists find difficult to help. Journal of neurology, neurosurgery, and psychiatry. 2004;75(12):1776-8.

9. Moene FC, Spinhoven P, Hoogduin KA, van Dyck R. A randomized controlled clinical trial of a hypnosis-based treatment for patients with conversion disorder, motor type. Int J Clin Exp Hypn. 2003;51(1):29-50.

10. Shapiro AP, Teasell RW. Behavioural interventions in the rehabilitation of acute v. chronic non-organic (conversion/factitious) motor disorders. The British journal of psychiatry : the journal of mental science. 2004;185:140-6.

11. Reuber M, Burness C, Howlett S, Brazier J, Grunewald R. Tailored psychotherapy for patients with functional neurological symptoms: a pilot study. Journal of psychosomatic research. 2007;63(6):625-32.

12. Goldstein LH, Chalder T, Chigwedere C, Khondoker MR, Moriarty J, Toone BK, et al. Cognitive-behavioral therapy for psychogenic nonepileptic seizures: a pilot RCT. Neurology. 2010;74(24):1986-94.

13. Ruddy R, House A. Psychosocial interventions for conversion disorder. Cochrane database of systematic reviews. 2005(4):CD005331.

14. Stone J, Binzer M, Sharpe M. Illness beliefs and locus of control: a comparison of patients with pseudoseizures and epilepsy. Journal of psychosomatic research. 2004;57(6):541-7.

15. Reid S, Crayford T, Patel A, Wessely S, Hotopf M. Frequent attenders in secondary care: a 3-year follow-up study of patients with medically unexplained symptoms. Psychological medicine. 2003;33(3):519-24.

16. Moene FC, Spinhoven P, Hoogduin KA, van Dyck R. A randomised controlled clinical trial on the additional effect of hypnosis in a comprehensive treatment 
programme for in-patients with conversion disorder of the motor type. Psychother Psychosom. 2002;71(2):66-76.

17. Richard J, Bouzourène K, Gallant S, Ricciardi P, Sudre P, Iten A, Burnand B. Validation et normes du SF-36 dans la populatio du canton du Vaud: Institut universitaire de médecine sociale et préventive. In: IMSP, editor. Lausanne2002.

18. Sharpe M, Stone J, Hibberd C, Warlow C, Duncan R, Coleman R, et al. Neurology out-patients with symptoms unexplained by disease: illness beliefs and financial benefits predict 1-year outcome. Psychological medicine. 2010;40(4):689-98.

19. Couprie W, Wijdicks EF, Rooijmans HG, van Gijn J. Outcome in conversion disorder: a follow up study. Journal of neurology, neurosurgery, and psychiatry. 1995;58(6):750-2.

20. Crimlisk HL, Bhatia K, Cope H, David A, Marsden CD, Ron MA. Slater revisited: 6 year follow up study of patients with medically unexplained motor symptoms. Bmj. $1998 ; 316(7131): 582-6$. 